\title{
A comparison of the efficiency of human embryo intestine, Hep 2 cells, and human embryo kidney cells for the primary isolation of ophthalmic viruses
}

\author{
W. D. CUBITT, ${ }^{1}$ D. A. MCSWIGGAN, ${ }^{1}$ U. THAKER, ${ }^{2}$ AND S. DAROUGAR ${ }^{2}$ \\ From the ${ }^{1}$ Public Health Laboratory and Department of Microbiology, Central Middlesex Hospital, \\ Park Royal, London NWIO 7NS, and the ${ }^{2}$ Subdepartment of Virology, Institute of Ophthalmology, \\ Judd Street, London WCI
}

SUMMARY A comparison has been made of the efficiency of 3 cell systems, human embryo kidney (HEK), Hep 2, and a continuous line of human embryo intestine (HEI), for the isolation of ophthalmic viruses. A total of 40 herpes simplex, 51 adenoviruses, and 2 vaccinia viruses were isolated from 323 specimens. HEK cells were found to be the optimal system, 85 out of $93(91 \%)$ of the viruses being detected in these cells alone. However, HEK cells are difficult to obtain, and therefore the use of a combination of the continuous cell lines HEI and Hep 2 is recommended as an alternative. $89 \%$ of the viruses were detected by this combination. The use of either HEI or Hep 2 cells alone was unsatisfactory.

Adenovirus and herpes simplex virus are the commonest causes of conjunctivitis and keratoconjunctivitis in the United Kingdom. ${ }^{1}$ It follows, therefore, that cell cultures used for the study of viral eye infections must be particularly sensitive to these 2 agents. In a previous study McSwiggan and colleagues $^{2}$ found human embryo kidney cells to be the best of the cell systems they tested for the primary isolation of viruses from the eye, 29 of 31 possible isolates being detected in these cells.

In recent years human embryo cells have become increasingly difficult to obtain. A search was therefore undertaken to find a readily available, easily maintained, continuous cell line acceptably efficient in the isolation of viruses from the eye. At the Institute of Ophthalmology interest centred on a line of Hep 2 cells, while at the Central Middlesex Hospital a pilot study indicated that a continuous cell line established from human embryo intestine (HEI) might meet the particular requirements of ophthalmic virology.

This study evaluates the comparative efficiency of these 2 readily available systems, separately and together, when measured against human embryo kidney cells, the optimum system.

Correspondence to $\mathrm{Mr}$ W. D. Cubitt.

\section{Materials and methods}

The clinical specimens used in this study consisted of conjunctival swabs collected from the eyes of patients referred to the External Eye Diseases Clinic, Moorfields Eye Hospital, London. These patients were suffering from acute conjunctivitis or keratoconjunctivitis consistent with an infection of viral origin.

The method of collection of specimens was identical to that previously described. ${ }^{2}$

Primary human embryo kidney. HEK cells were grown in test-tubes seeded at $2 \times 10^{5}$ cells $/ \mathrm{ml}$ with Eagle's basal medium (EBM) (Wellcome Reagents), supplemented with $0.1 \%$ sodium bicarbonate, $10 \%$ newborn calf serum (NBCS) (Flow Laboratories), penicillin 100 units $/ \mathrm{ml}$, and streptomycin $100 \mu \mathrm{g} / \mathrm{ml}$. Once the cells had formed a confluent monolayer they were maintained on maintenance medium (MM)-Medium 199-supplemented with $2 \%$ NBCS, $0.15 \%$ sodium bicarbonate, and antibiotics.

Continuous human embryo intestine (Flow). $7.5 \times 10^{4}$ HEI cells/ml were seeded into test-tubes with $\mathrm{EBM}$, $15 \%$ NBCS, $0.088 \%$ sodium bicarbonate, and antibiotics. $0.03 \%$ glutamine was essential to obtain confluent monolayers. MM was identical to that used for HEK. 
Hep 2 cells. The cells were propagated in Eagle's MEM with $10 \%$ fetal bovine serum, vancomycin $(50 \mu \mathrm{g} / \mathrm{ml})$, streptomycin $(100 \mu \mathrm{g} / \mathrm{ml})$, and vitamins and glutamine $(0.01 \%)$; they were maintained in similar medium but with $3 \%$ serum. The cell monolayers were prepared by adding to each test-tube a $1 \mathrm{ml}$ aliquot of cell suspension containing $5 \times 10^{4}$ cells/ $\mathrm{ml}$. These were incubated for 2 days at $33^{\circ} \mathrm{C}$.

Inoculation and investigation of cell cultures. Tubes of HEK and HEI cells were prepared at the Public Health Laboratory, Central Middlesex Hospital (CMH) and transferred to the Virus Laboratory, Institute of Ophthalmology, each Monday. Cultures were then maintained stationary at $33^{\circ} \mathrm{C}$ until required. The maintenance medium was replaced on HEI cells every other day to prevent medium becoming acidic. Hep 2 cells were prepared at the Institute of Ophthalmology. The specimens were extracted in transport medium and $0.2 \mathrm{ml}$ of this inoculated into 2 tubes each of HEK, HEI, and Hep 2 cells; these were incubated at $33^{\circ} \mathrm{C}$ on roller drums. All cultures were maintained and examined at the Institute of Ophthalmology until the Monday following inoculation, when HEK and HEI cells were returned to $\mathrm{CMH}$ for further investigation. Hep 2 cells were retained for investigation and processing at the Institute. All the cell systems were examined every second weekday. Cultures not showing cytopathic effect were harvested at 7 days and the cells and medium passed into tubes containing fresh cells of the same type. This process was repeated after a further 7 days. If there was no evidence of virus replication by production of a cytopathic effect on cells by 21 days, cultures were then considered to be negative.

Cultures showing evidence of viral effects on the cells were further examined to determine the identity of the type of virus. As an initial procedure adenoviruses were differentiated from herpes simplex virus by indirect immunofluorescence or by electron microscopy. Adenoviruses were then serotyped in HEI or Hep 2 cells grown in microtitre plates with neutralising sera (Division of Microbiological Reagents and Quality Control, Central Public Health Laboratory, Colindale) types 1-31 distributed in 7 pools.

Table 1 Isolation and identification of adenoviruses

\begin{tabular}{lrrrrrrrrrrrr}
\hline Type & 3 & 4 & 5 & 7 & 8 & 11 & 13 & 16 & 19 & 30 & Untypable & Total \\
\hline $\begin{array}{l}\text { No. of } \\
\text { isolates }\end{array}$ & 4 & 15 & 1 & 1 & 8 & 4 & 6 & 1 & 2 & 4 & 5 & 51 \\
\hline HEK & 4 & 9 & 1 & 1 & 8 & 4 & 6 & 1 & 1 & 4 & 5 & 44 \\
HEI & 4 & 10 & 1 & 1 & 7 & 4 & 5 & 1 & 2 & 3 & 4 & 42 \\
HEP & 4 & 12 & 1 & 1 & 7 & 4 & 5 & 1 & 1 & 3 & 4 & 45 \\
\hline
\end{tabular}

Table 2 Comparison of sensitivity of HEK, $H E I$, and Hep 2 for the primary isolation of viruses

\begin{tabular}{cllll}
\hline \multicolumn{5}{c}{ Type of virus isolated } \\
\cline { 2 - 4 } Type of cell & $\begin{array}{l}\text { Herpes } \\
\text { simplex }(40)^{*}\end{array}$ & $\begin{array}{l}\text { Adenovirus } \\
(51)^{*}\end{array}$ & $\begin{array}{l}\text { Vaccinia } \\
(2)^{*}\end{array}$ & $\begin{array}{l}\text { Total } \\
(93)^{*}\end{array}$ \\
\hline HEK & 39 & 44 & 2 & $85(91 \%)$ \\
Hep 2 & 27 & 43 & 2 & $72(77 \%)$ \\
HEI & 25 & 42 & 2 & $69(74 \%)$ \\
Hep 2 + HEK & 40 & 49 & 2 & $91(98 \%)$ \\
HEK + HEI & 39 & 49 & 2 & $90(97 \%)$ \\
Hep 2 + HEI & 32 & 49 & 2 & $83(89 \%)$ \\
Total isolation rate $=93 / 323(28 \%)$, Hep + HEK + HEI & \\
\hline
\end{tabular}

*The numbers in brackets refer to total isolates.

\section{Results}

Three hundred and twenty-three specimens were inoculated into each of the 3 cell systems.

In total 93 viruses were isolated, giving an overall isolation rate of $28 \%$. Of these, 51 were adenoviruses, 40 herpes simplex viruses, and 2 vaccinia virus. The serotypes of the adenoviruses and their distribution according to cell system are shown in Table 1. Serotypes 4, 8, and 13 account for over half $(56 \%)$ of the types isolated; there was no significant difference in the efficiency of any of the 3 cell systems for the isolation of any particular adenovirus serotype.

When the relative efficiency of each cell culture system is compared (Table 2), it can be seen that HEK cells were significantly more sensitive than either Hep 2 or HEI cells, accounting for $91 \%$ of the total viruses isolated against $77 \%$ and $74 \%$ respectively. This difference is, however, entirely accounted for by the superiority of HEK cells for the primary isolation of herpes simplex viruses. Thirty-nine out of the 40 isolates were detected in this cell system in contrast with $27(68 \%)$ in Hep 2 cells and $25(62.5 \%)$ in HEI. When the results of the latter 2 systems are taken in combination, 32/40 $(80 \%)$ isolates of herpes simplex virus were attained,

Table 3 Comparison of the mean time and number of passages necessary to detect CPE in $H E K, H E I$, and Hep 2

\begin{tabular}{|c|c|c|c|c|}
\hline \multirow[b]{2}{*}{ Cell system } & \multicolumn{3}{|c|}{ Cell cultures } & \multirow{2}{*}{$\begin{array}{l}\text { Mean time } \pm S D \\
\text { to detect } C P E\end{array}$} \\
\hline & Initial & 1st Pass & 2nd Pass & \\
\hline \multicolumn{5}{|c|}{ Herpes simplex virus } \\
\hline HEK & 39 & - & - & $2.7 \pm 1.9$ days \\
\hline HEI & 21 & 4 & - & $4.9 \pm 3.8$ days \\
\hline Hep 2 & 15 & 7 & 5 & $7 \cdot 5 \pm 5.6$ days \\
\hline \multicolumn{5}{|c|}{ Adenovirus } \\
\hline HEK & 37 & 5 & 2 & $6.2 \pm 4.4$ days \\
\hline HEI & 24 & 13 & 5 & $7 \cdot 6 \pm 4.7$ days \\
\hline Hep 2 & 18 & 15 & 10 & $9 \cdot 3 \pm 5 \cdot 3$ days \\
\hline
\end{tabular}


but this is still significantly inferior to the use of HEK cells alone.

Table 3 compares the number of passages required before a cytopathic effect was seen and the mean time at which this first appeared. The most satisfactory cell system for the isolation of HSV was HEK, all 39 isolates being found within a week of primary inoculation. HEI were less efficient, 4 of the 25 isolates requiring 1 passage before a CPE was obtained. Hep 2 were the least sensitive; $12 / 27$ isolates were found only after 1 passage or more. A similar situation was found for adenoviruses, but the mean times for the appearance of CPE were longer. Hep 2 were again the least sensitive; $10 / 43$ isolates appeared after 2 passages, whereas only $5 / 42$ isolates needed more than 1 passage in HEI.

\section{Discussion}

This study confirms a previous report ${ }^{2}$ that HEK cells provide the most valuable system for the investigation of ophthalmic virus infections. $91 \%$ of the viruses isolated in this study were detected in HEK cells; in the majority of cases it was possible to report to the clinician within a week of receiving the specimens.

Although the combination of HEI and Hep 2 cells detected 49 out of the 51 adenoviruses found during the study, results were frequently not available for a week or more owing to the slow development of cellular changes, indicating virus replication, in these systems.

The prospect of specific, effective treatment for herpes simplex infection ${ }^{3}$ makes the rapid and reliable identification of this virus a matter of special and increasing importance. In this regard HEK cells were shown to be markedly superior to HEI and Hep 2 cells, the latter failing to detect $20 \%$ of the herpes infections, with possible serious consequences for these patients. The difficulty in maintaining a supply of HEK cells for primary isolation remains a serious disadvantage. ${ }^{2}$ In this respect HEI and Hep 2 cells may play a useful part as HEK-sparing-cells, as they can be used for serological typing of ophthalmic viruses once primary isolation has been achieved. The use of cells grown in microplates and pools of adenovirus typing sera were found to be another economical and effective way of identifying the various types of adenoviruses isolated in this study. The value of immunofluorescence for the differentiation of herpes and adenoviruses was substantiated by the electron microscopy findings. Seventy isolates examined 'blindly' by both methods showed complete agreement. This is a reassuring finding, as immunofluorescence is much more widely available than electron microscopy.

In conclusion, the need exists for a continuous cell line as sensitive as HEK cells for the primary isolation of ophthalmic viruses.

This study was in part supported by a grant from the Locally Organised Clinical Research Scheme, Moorfields Eye Hospital, City Road, London EC1.

The technical assistance of Mrs B. Mitchell is gratefully acknowledged.

\section{References}

1 Jones BR, Andrews BE, Henderson WG, Schofield PB. The pattern of conjunctivitis at Moorfields during 1956. Trans Ophthalmol Soc UK 1957; 77: 291-305.

2 McSwiggan DA, Darougar S, Rahman AFMS, Gibson JA. Comparison of the sensitivity of human embryo kidney cells, HeLa cells, and W138 cells for the primary isolation of viruses from the eye. J Clin Pathol 1975; 28: 410-3.

3 Jones BR, Coster DJ, Fison PN, Thompson GM, Cobo LM, Falcon MG. Efficacy of acycloguanosine (Wellcome 248U) against Herpes simplex corneal ulcers. Lancet 1979; i: $243-4$. 